\title{
On a generalization of the Levin-May Theorem
}

\section{JAN ČERMÁK and JIŘí JÁNSKÝ}

\author{
ABSTRACT. \\ The paper discusses a distribution of the zeros of the polynomial

$$
p(\lambda) \equiv \lambda^{k+1}-\lambda^{k}+q, \quad q \in \mathbb{R}, \quad k \in \mathbb{Z}^{+}
$$ \\ with respect to the unit circle. This problem is of theoretic as well as practical importance which motivated $\mathrm{S}$. \\ A. Levin and R. May to formulate a necessary and sufficient condition guaranteeing the location of all the zeros \\ of $p(\lambda)$ inside the unit circle. We give a simple alternate proof of their criterion and, as the main result, present \\ a complete list of all possible zero distributions of $p(\lambda)$ with respect to this circle.
}

Acknowledgements. The research was supported by the grant P201/11/0768 of the Czech Science Foundation and by the project FSI-S-11-3 of Brno University of Technology.

\section{REFERENCES}

[1] Bellen, A. and Zennaro, M., Numerical Methods For Delay Differential Equations, Numerical Mathematics and Scientific Computation, The Clarendon Press, Oxford University Press, New York, 2003

[2] Bistritz, Y., Zero location of polynomials with respect to the unit-circle unhampered by nonessential singularities, IEEE Trans. Circuits Syst., 49 (2002), No. 3, 305-314

[3] Čermák, J., Jánský, J. and Kundrát, P., On necessary and sufficient conditions for the asymptotic stability of higher order linear difference equations, J. Difference Equ. Appl., 18 (2012), No. 11, 1781-1800

[4] Elaydi, S., An Introduction to Difference Equations, 3rd ed., Undergraduate Texts in Mathematics, Springer, New York, 2005

[5] Jury, E. I., Theory and Application of The Z-Transform Methods, Wiley, New York, 1964

[6] Kim, S. H. and Park, C. W., On the zeros of certain self-reciprocal polynomials, J. Math. Anal. Appl., 339 (2008), 240-247.

[7] Kipnis, M. M. and Nigmatullin, R. M., Stability of the trinomial linear difference equations with two delays, Autom. Remote Control, 65 (2004), No. 11, 1710-1723

[8] Kipnis, M. M. and Levitskaya, I. S., Stability of delay difference and differential equations: Similarities and distinctions, in Proceedings of the International Conference Difference Equations, Special Functions and Orthogonal Polynomials, Munich, Germany, 25-30 July 2005, World Scientific, Singapore, 2007, 315-324

[9] Kuruklis, S. A., The asymptotic stability of $x_{n+1}-a x_{n}+b x_{n-k}=0$, J. Math. Anal. Appl., 188 (1994), 719-731

[10] Levin, S. A. and May, R., A note on difference-delay equations, Theor. Popul. Biol., 9 (1976), 178-187

[11] Marden, M., Geometry of Polynomials, Mathematical Surveys and Monographs, No. 3, Providence, 1966

[12] Matsunaga, H. and Hajiri, C., Exact stability sets for a linear difference system with diagonal delay, J. Math. Anal. Appl., 369 (2010), 616-622

[13] Pal, D. and Kailath, T., A generalization of the Schur-Cohn test: the singular cases, in Proceedings of the 33rd Midwest Symposium on Circuits and Systems, Calgary, Canada, 12-15 August, 1990, 64-67

Received: 14.11.2012; In revised form: 11.06.2013; Accepted: 21.06.2013

2010 Mathematics Subject Classification. Primary 26C10, Secondary 39A30.

Key words and phrases. Higher order linear difference equation, characteristic polynomial, zero distribution, asymptotic stability.

Corresponding author: Jan Čermák; cermak.j@fme.vutbr.cz 
BRNO UNIVERSITY OF TECHNOLOGY

FACULTY OF MECHANICAL ENGINEERING, INSTITUTE OF MATHEMATICS

TECHNICKÁ 2, 61669 BRNO, CZECH REPUBLIC

E-mail address: cermak.j@fme.vutbr.cz

E-mail address: yjansk 04 @stud. fme.vutbr.cz 